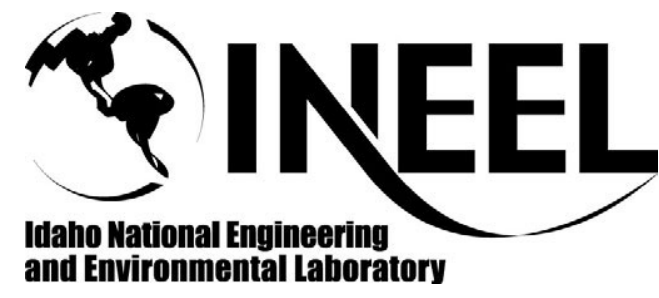

INEEL/CON-01-00567

PREPRINT

Preliminary Identification of Accident Initiating Events for IFE Power Plants

Lee C. Cadwallader, INEEL

Jeffery F. Latkowski, LLNL

October 2, 2001

Nineteenth IEEE/NPSS Symposium on Fusion Engineering (SOFE '01)

This is a preprint of a paper intended for publication in a journal or proceedings. Since changes may be made before publication, this preprint should not be cited or reproduced without permission of the author.

This document was prepared as an account of work sponsored by an agency of the United States Government. Neither the United States Government nor any agency thereof, or any of their employees, makes any warranty, expressed or implied, or assumes any legal liability or responsibility for any third party's use, or the results of such use, of any information, apparatus, product or process disclosed in this report, or represents that its use by such third party would not infringe privately owned rights. The views expressed in this paper are not necessarily those of the U.S. Government or the sponsoring agency. 


\title{
Preliminary Identification of Accident Initiating Events for IFE Power Plants
}

\author{
Lee C. Cadwallader, INEEL, and Jeffery F. Latkowski, $L L N L$
}

\begin{abstract}
This paper presents initial results of a task to identify accident initiating events for inertial fusion energy (IFE) power plant designs. Initiating events (IEs) are a fundamental building block of a probabilistic risk assessment; they are the 'accident starters' that are analyzed to determine the risks posed to members of the public in the vicinity of the power plant. The IE results for the SOMBRERO design are presented in tabular form. The SOMBRERO design was analyzed since it is representative of dry chamber wall, laser driven designs. This work is used to characterize IFE plant risk and to identify potential design changes that would mitigate the plant risk.
\end{abstract}

\section{INTRODUCTION}

$\mathrm{I}$ nitiating events (IEs) are a fundamental building block of a probabilistic risk assessment; they are the 'accident starters' which are analyzed to determine the risks posed to members of the public in the vicinity of the power plant. Completeness in IE identification is essential to determining a risk profile for a facility. Therefore, a combination of techniques was used for this analysis to ensure completeness [1]. These techniques included a Preliminary Hazards Analysis (PHA) to identify energy sources and hazards, a review of historical safety reports on IFE plant designs, and a review of Department of Energy (DOE) occurrence reports from existing laser and ion beam experiments. A Master Logic Diagram (MLD) for the SOMBRERO $\mathrm{KrF}$ laser fusion plant design was also constructed and analyzed to identify IEs. MLD construction for an ion beam fusion plant (the HYLIFE-II design) is in progress and will be published separately [2]. The MLD was used to identify the IEs that could result in an off-site release of hazardous toxicological or radiological material. The initial IE results for the SOMBRERO design concept are presented in tabular form.

\section{INITIATOR IDENTIFICATION}

Several techniques were used for this IE analysis. The PHA, review of safety reports and operational occurrences, and MLD have been used in this work to ensure completeness for the given design detail. These techniques are described below.

\section{A. Preliminary Hazards Analysis}

This is a qualitative analysis technique to address the energy sources, hazardous materials, and radioactivity used or stored in a facility. The PHA is best used on facilities in conceptual design or on those operational facilities that have not had an accident analysis performed. The PHA for a generic IFE power plant concentrated on radioactive, toxic, flammable, and explosive material releases; tritium fuel releases; and uncontrolled electrical energy releases.

\section{B. Historical data evaluation}

Past safety reports and safety sections of inertial fusion power plant design studies were reviewed to compile lists of IEs. The past reports on design studies such as Prometheus, HIBALL, Osiris, SOMBRERO, HYLIFE-II, and LIBRA did not focus on risk assessment or IEs, but rather on the safety analysis approach of consequences from large-scale, hypothetical release events. Two worst-case events were cited in the safety work for IFE designs; these events were typically large loss of coolant accidents that also breach containment, and total releases of mobilizable tritium fuel.

The National Ignition Facility safety analysis report was reviewed [3]. Off-site consequence events applicable to fusion power plant designs were tritium releases and natural phenomena (high winds, site floods, earthquakes, and a light aircraft crash scenario). The Tritium Systems Test Assembly safety analysis report [4] was also reviewed for insights into tritium handling IEs. These IEs included: rupture or large leak of tritium from experiment confinement with secondary confinement failure (release with and without subsequent fire); rupture of a cryopump with loss of secondary confinement (with and without subsequent fire); rupture of cryogenic distillation columns to the vacuum jacket with jacket breach (with and without subsequent fire); and tritium transfer line leakage with and without secondary confinement failure (with and without subsequent fire).

The DOE occurrence report database was searched for historical events from laser and ion beam fusion experiments. The results were two crane load drop events (a cathode tip and a laser lens), three personnel contamination events, a personnel electrical shock event, two facility power outages (one for 4.7 hours, the other for 0.3 hours), three optics damage or optics failure events, a $13.8 \mathrm{kV}$ power supply electrical arcing event, and one $\mathrm{HCl}$ toxic gas leakage event. These events were surprisingly relevant for this IE study. Crane load drops must be considered even if a power plant operates with much fewer 
modifications or equipment replacements than experiments. Power plant equipment will be more massive than experiment equipment since power plant equipment handles higher throughputs, higher energy densities, etc. Electrical power outages are not rare events and must be accounted for in a risk assessment. Optics damage events must be examined for public safety issues since the beam line could be a pathway for fuel debris and activated dust to escape confinement. The electrical arc event cannot be entirely precluded by future design since equipment can wear, insulation can fail, etc. The electrical arc may not pose a hazard to the public because of the use of exclusion areas around outdoor equipment, the facility perimeter fence and switchyard fence, and the building confinement for indoor equipment. Toxic gas leaks must be analyzed for their consequences to the public and workers.

\section{Master Logic Diagram}

The MLD is a top down approach of postulating an off-site release of hazardous material and then determining what failures must occur to result in such a release. A preliminary MLD for the SOMBRERO plant conceptual design [5] was completed and analyzed for its initiating events.

The MLD is built in successive levels, starting at the top of a tree structure. The first horizontal level is the public hazard, defined as an off-site release of hazardous material. The next level is specification of the release pathway, typically the building where a release originates. The third level is the release origin, the system that confines radioactive or hazardous material. Level three is necessary to account for the many systems in a fusion plant that contain radioactive materials and to allow introduction of the concept of mobilization of radioactive species. The fourth level lists the release species. This level was specified because of the combined nature of the inventories in the reactor chamber and in waste handling and because there can be temperature and oxidation/volatilization restrictions on mobilization and release of some species. These restrictions need to be delineated for source term assessment. Level five identifies the barriers to release, generally mobilization and the engineered physical barriers. Some of the inventories in the IFE reactor are readily mobile (gases and liquids), but some are bound in the solid structure and require significant heating and the presence of oxygen to be mobilized by volatilization.

Level six identifies the safety functions for that branch of the diagram. The safety functions are those acts or functions that must be carried out to prevent off-site releases. Suggested safety functions for IFE power plants, based on magnetic fusion experience [6], are listed below:

\section{Reduce inventories}

2. Provide confinement barriers

3. Ensure decay heat removal

4. Control hydrogen inventories and chemical reactions

5. Control effects of magnetic energy

6. Control effects of coolant energy
7. Monitor status of safety functions and safety related parameters

8. Provide support services to ensure safety functions

These safety functions are not listed in order of importance; they are equally important. For the IFE MLD, only the safety functions 2 through 6 are included since these deal directly with the plant process and safety systems. Safety function 1 is viewed as an engineering control in the design process. While safety functions 7 and 8 are important for maintaining plant control, they are not necessary for identifying initiating events in an MLD. That is, loss of monitoring or support services does not directly lead to a radiological or toxicological release; their loss typically leads to an orderly plant shutdown. Not all safety functions were used in each branch of the MLD since some functions do not apply to particular branches.

The final level of the MLD identifies events that can fail the safety functions. These events were labeled "failure events". These events can be IEs for the conceptual power plant. If an AND gate was used in the tree, then the failure events must be compounded to yield an initiator. The most important failure events are those found on each input to an AND gate. A representative portion of the MLD is shown in Fig. 1. The complete MLD is given in [2].

\section{Compiled IE list}

The initial list of IEs for the SOMBRERO plant design that have been identified from these various analysis methods is given in Table 1. Further analysis is needed to determine which of these events are significant, and which events can be grouped together into event categories.

\section{CONCLUSIONS}

This task has produced a preliminary list of accident initiating events for the SOMBRERO dry wall, $\mathrm{KrF}$ laser driven IFE power plant design. This preliminary list of IEs supports safety assessment and creates a basic framework of IEs to consider in future risk characterization of new plant designs. Any IEs that yield unacceptably high consequences can be examined to identify potential design changes that would limit consequences.

\section{ACKNOWLEDGMENT}

This work was prepared for the US Department of Energy (DOE), Office of Fusion Energy Sciences, under the DOE Idaho Field Office contract number DE-AC07-99ID13727. This paper is also identified as INEEL/CON-2001-567.

\section{REFERENCES}

[1] L C. Cadwallader, "Identification and Selection of Initiating Events for Experimental Fusion Facilities," Proceedings of the IEEE Thirteenth Symposium on Fusion Engineering, Oct. 2-6, 1989, Knoxville, TN, pp. 1103-1107. 
[2] L. C. Cadwallader and J. F. Latkowski, Preliminary Identification of Accident Initiating Events for Inertial Fusion Energy Power Plant Designs, INEEL/EXT-01-1600, to be published.

[3] National Ignition Facility Preliminary Safety Analysis Report, UCRLID-123759, Lawrence Livermore National Laboratory, Sept. 1996.

[4] R. V. Carlson, "Safety Analysis Report for the Tritium Systems Test Assembly," Fusion Technology, $\underline{4}$, 1983, pp. 544-549.
[5] Osiris and SOMBRERO Inertial Confinement Fusion Power Plant Designs, DOE/ER/54100-1 and DOE/ER/54100-2, Mar. 1992.

[6] L. C. Cadwallader, N. P. Taylor and A. E. Poucet, "Preliminary Master Logic Diagram for ITER Operation," Probabilistic Safety Assessment and Management, PSAM4, New York, NY, Sept. 13-17, 1998, Springer Verlag Publishers, 1998, volume 1, pp. 253-258. 
Level 1

Public

Hazard
Excessive Off-Site

Release of

Hazardous Material

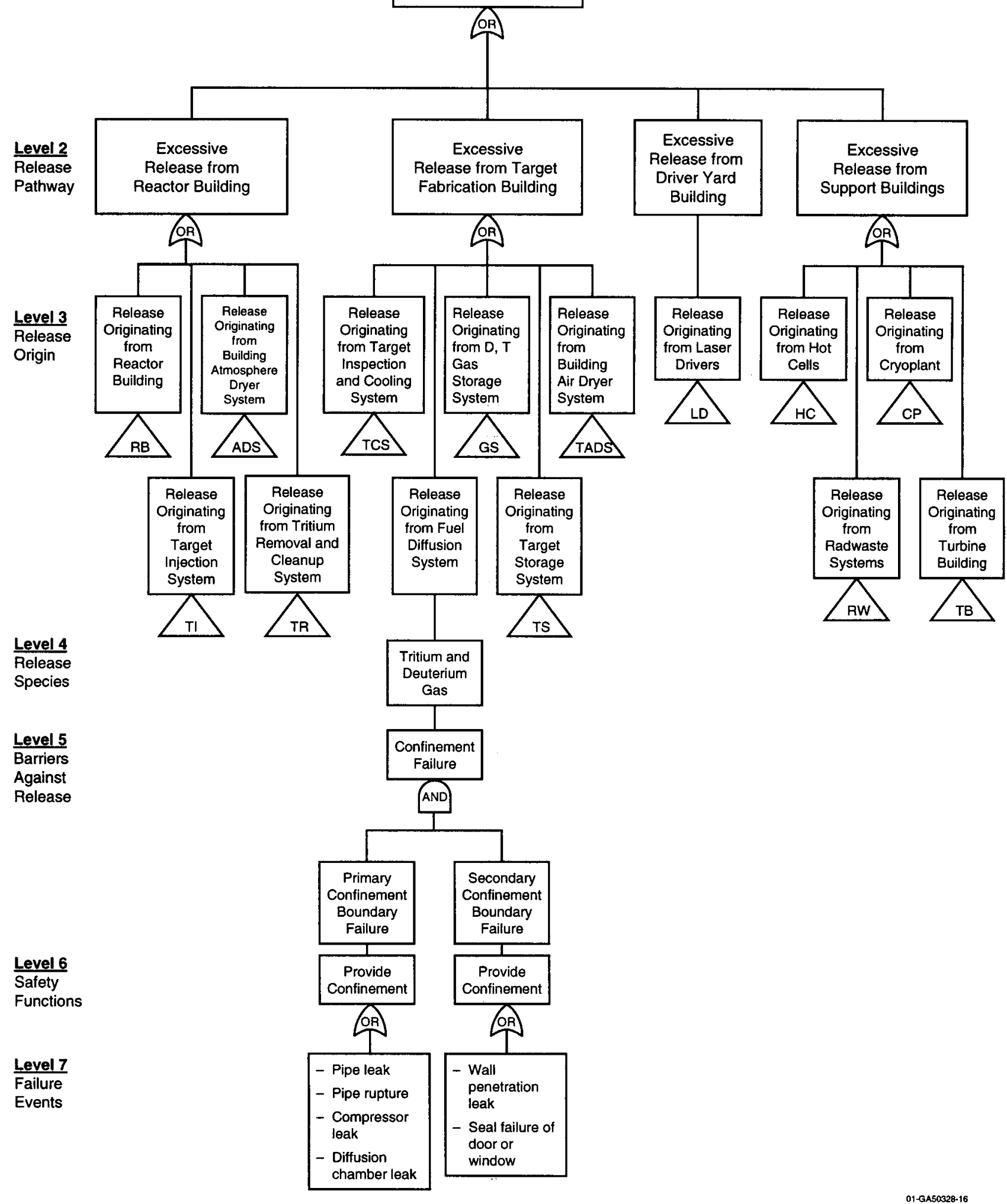

Figure 1. The preliminary Master Logic Diagram for the SOMBRERO design, showing one branch expanded to level 7.

Table 1. Preliminary List of Accident Initiating Events for the SOMBRERO IFE Power Plant Design 


\section{plant events}

-Loss of chamber wall / shield coolant

-Loss of chamber afterheat removal coolant

-Loss of chamber wall / shield coolant heat sink

-Loss of confinement building integrity

-Driver reactions with IFE chamber walls (laser beams strike or are reflected to walls)

-Loss of off-site power
-Loss of chamber wall / shield coolant flow

-Loss of chamber afterheat removal coolant flow

-Loss of tritium purge from shield $\mathrm{Li}_{2} \mathrm{O}$ coolant

-Loss of $\mathrm{KrF}$ lasing gas

-DT fuel gas explosion

-Facility blackout event

-Loss of tritium confinement (from pellet injection, from debris cleanup, from storage, or from target fabrication)

-Large loss of cryogen $\quad$ Radwaste system release

\section{natural phenomena and other events of concern}

-Fire within facility (air atmosphere rooms)

-Flood within facility (coolant or other fluid release)

•High straight winds

-Snow or ice accumulation

-Aircraft impact

-In-plant vehicle accident (forklift, etc.)

-On-site train accident

-Externally-generated missiles (turbine blade, hail, etc.)
-Fire outside of facility (e.g., forest fire, range fire)

-Site flood (e.g., from river, high rainfall, runoff)

-Tornado (or hurricane, seiche)

-Lightning strike

- On-site truck accident

-Barge or ship accident (if sited near a body of water)

-Tritium transport accident

-Crane load drop

-Major accident in close proximity to facility: chemical process plant event, fossil fueled power plant event, industrial or manufacturing plant event, military base event, 
nuclear fission power plant event, pipeline leak or rupture, rail car derailment event, highway truck accident event 